Chapter 7

\title{
Socialization Goals of Mothers and Grandmothers of Children in Institutional Shelter Situation in the North of Brazil
}

\author{
Lília lêda Chaves Cavalcante and \\ Celina Maria Colino Magalhães
}

Additional information is available at the end of the chapter

http://dx.doi.org/10.5772/57328

\section{Introduction}

The rise of parenthood as an important study field nowadays reveals contributions of research in psychology, sociology, and anthropology areas along with its interfaces (Piccinini \& Alvarenga, 2012).The increase of studies on this theme, and its type of expression in different child developmental contexts, is associated to the understanding that this is a social and culturally organized process.

Parenthood may be defined, broadly, as several activities with the purpose of assuring the child's survival and development, so he/she may grow up in a safe and protected environment (Barroso \& Machado, 2011). In such conditions, the child is expected to benefit from material and emotional comfort, in addition to receive motivation to autonomy (Maccoby, 2000). Consequently, among other tasks imposed to parenthood, maybe the most important one is the challenge for a generation (parents) to prepare a younger generation (children), possibly being helped or replaced by a previous generation (grandparents), with the purpose to make the child able to face risky situations, and socioeconomic and psychosocial difficulties along the developmental pathway, assuring its survival and independence (Barroso \& Machado, 2011).

Parenthood is a socially built category and its conceptual definition tends to emphasize the importance of subjective impressions (Virasiri, Yunibhand \& Chaiyawat, 2011) and/or the importance of eco-cultural conditions characteristic of certain developmental contexts (Keller, Voelker, \& Yovsi, 2005). That is because the conceptions and practices that define it vary across 
cultures, along with individual and family beliefs and moral values which constitute parental ethnotheories and the socialization goals related to it (Keller, Voelker \& Yovsi, 2005).

Several researches have investigated, so far, the role of culture on the formulation of this concept (Harkness \& Super, 1996; Kagitcibasi, 2005), besides such researches have highlighted the role cultural beliefs have on its delimitation. However, even though the cultural differences have been pointed out on the parenthood process, it is not possible to disregard the resemblance of how parents plan socialization strategies and educational practices that, according to their point of view, facilitate the survival of its offspring and their preparation for a more independent life (Keller et al., 2005)..

In the case of human babies, there are enough evidence that primary care have a clearer survival value than in other species. The processes involved in parenthood are vital for their survival. They are performed by parents through functional activities, that direct children towards self-improvement, because they belong to a species that has been beneficiated from social learning and cultural transmission on its evolutionary process. In accordance to Kagitcibasi (2005), generation after generation parents are expected to grant the offspring survival and their intellectual, social, and emotional autonomy, but certainly on the molds recognized and reckoned by the culture in which they are inserted.

Some studies (Keller, Voelker, \& Yovsi, 2005; Mimi McEvoy, Lee, O’Neill, Groisman, RobertsButelman, Dinghra \& Porder, K., 2005) have demonstrated that parenthood is linked to a set of cognitions and parental practices that might be distinguished or similar, depending on the meaning given by the context they live and the activities they do for the child socialization. In these terms, parenthood may and must be investigated by the confluence of sociocultural and psychological processes present on the termed socialization goals (Diniz \& Salomão, 2010).

Socialization goals refer to, according to Moinhos, Lordelo e Seidl-de-Moura (2007), what parents expect their child to be in the future and what they imagine it must be done to achieve this purpose. They are related to how parents guide their children in attaining the tasks imposed by the development, based on styles and parental practices that are particular from the individual or family, but always in agreement to cultural beliefs and moral values that are socially instituted.

The studies performed by Keller, Lamm, Abels, Yovsi, Borke, Jensen et al. (2006), but also Zucker e Howes (2009), discuss the practices used for raising children that represent a certain cultural model and parental conviction about the best way to take care and educate children. In the first study, the researchers used a questionnaire with ten socialization goals, from which five were in reference to preparation for autonomy, the others were of relational aspects. The researchers interviewed mothers from different cultural contexts, hence, who had grown up under different influences of beliefs that emphasize autonomy and/or interdependence in the child socialization. The participants were asked to give their opinions on which of the goals presented could be reached by three-year-old children, as for example, developing selfconfidence (autonomous model), and obeying older people (rational model). The results show that among mothers the autonomous-relational model was prominent, which represents an intermediate position, which means that sometimes they were sure of the children's ability to 
accomplish the goals in the expected period, other times they questioned their ability for that. This and other results suggest that several social changes are leading families (mainly those that live in urban contexts with educated population) to review parental roles and the way of living, reflecting on how parents think the child socialization, which are presumably important for preparing children for future achievements.

In the same way, Leyendecker, Harwood, Lamb e Sholmerich (2002)investigated the socialization goals stated by Latin mothers that migrated to the United States and other American mothers with European American backgrounds, as well as their evaluation of daily situations considered desirable or undesirable for accomplishing such goals. The researchers used a questionnaire composed by questions about the socialization goals they define for their children, the answers were categorized fivefold: Self-maximization (SM), Self-control (SC), Emotionality (E), Social Expectancy (SE), and Proper Demeanor (PD). The results show that Latin mothers emphasize qualities that underline the goal of having children that demonstrate proper demeanor (which works as social approval). On the other hand, American mothers with European American backgrounds emphasize their ambition in terms of their selfmaximization and self-control.

In Brazil similar studies were performed in the last two decades in different states: Bahia (Moinhos et al. 2007), Pará (Silva \& Magalhães, 2011), and Santa Catarina (Westphal et al., 2011). The results demonstrate that the most common socialization goals represent the characteristics of the cultural environment the caretakers live. The results also indicate how complex it can be the challenge of considering a single cultural context of parenthood that represents the Brazilian context, taking into consideration that from the North to the South of the country it is noticed a predominance of autonomous-relational cultural model. Despite the fact that such model is typical of the profound social transformation happening in recent years, this model cannot be considered homogeneous, for the reason that studies have revealed different settings of socialization goals and strategies due to particularities of the socio-cultural context where the investigations were performed.

In a study that involved 350 mothers from five demographic regions of Brazil Moura, Lordelo, Vieira, Piccinnini, Siqueira, Magalhães et al (2008) analyzed differences and similarities in the definitions of socialization goals. The data were collected through and instrument elaborated by Harwood et al. (1999), with the aim of identifying the qualities mothers would like their children to have when adults. According to the results, most Brazilian mothers tend to prioritize the self-maximization goals, which may be due to cultural patterns that value the autonomy and independence in the children socialization process, in addition to those that lead to the development of goals that emphasize the importance for the children to be raised in a way to adapt to the social expectations of families and/or the group in which they live, strengthening the value of interdependence and group belongingness.

According to Para Kagitcibasi (2005),, the responsibility attributed to parents of making the children more autonomous since early childhood, along its developmental pathway, certainly depends on the level of influence of cultural models on the setting assumed for parenthood on each society and time. In this sense, the socialization goals may highlight the value cultural 
models have that appreciate the independence and/or the interdependence in the children socialization, having different weight on its development, in different scopes.

Therefore, it is supposed that if it is true that the societies characterized as western, educated, industrialized, rich, and democratic, or WEIRD, as defined by Henrich, Heine e Norenzayan (2010), treasure the individual's autonomy since the early years of age, and build a path of continuous personal self-maximization, it may also be correct to state that parents may not achieve the socialization goals that they have themselves designed for their children. Autonomy, here understood as a product of opportunities offered together by family, society, and government, may be the most important characteristics of a socialized adult, an ideal standard pursued since childhood, but probably reached by a small parcel of children, more precisely the ones that live in less than $16 \%$ of the countries. In addition, even this small part of countries, considered rich and educated, may face difficulties to accomplish this ideal life, due to the global economic crisis that has been happening for decades and impoverishing families, reducing the chances for parents to watch their children be raised in a safe environment that stimulate an autonomous life (Unicef, 2012). Most countries of Africa, Asia, Latin America, and Caribbean Islands, children have been raised and educated in families that deal with many sorts of difficulties, crises and risks (Sarti, 2010; Vegas \& Santibáñez, 2010). Poverty, in particular, marked by the lack of possessions and sufficient income to support the children, make parents more vulnerable to addictions, violence, diseases, chronic unemployment, that impair the parental roles.

In the present study it is emphasized that poverty, in its multiple aspects, may take away from parents the ability to establish socialization goals and make them to follow strategies that cannot be pursued satisfactorily. In other words, parents design socialization strategies under the influence of eco-cultural conditions that, several times, are responsible for their impossibility. That is because poverty brings for both parents and children a series of limitations and obstacles that make the development path an even harder and more complex process. Some studies consider poverty to have prejudicial effects, mainly on the early development, but also for the future life (Vegas \& Santibáñez, 2010; Bronfenbrenner, 1979).

Historically, poverty, above all the precarious socio-economic condition of the family (low levels of education, income and health), has been pointed as the main reason, among others (Vegas \& Santibáñez, 2010; Bronfenbrenner, 1979), for parents to fail or neglect the parental role. Such fact has made thousands of children in Brazil, and around the world, to go through severe personal and social vulnerable conditions, hence forcing the society and the government to find alternatives for the parental care (provisory, or long-stay shelters, foster-care systems), as exemplified by Roy e Rutter (2006) e Cavalcante, Santos e Magalhães (2012). In very common situations it is noted that parents cannot protect and support the basic needs of their children, for they didn't have their own needs attended since birth, making them believe the shelter may provide at the same time, cover, protection and the necessary care with health and education.

Children around the world have been sent away from their daily living with biological parents, because, according to the child protection legislation from their country, the parents failed constantly to assure their protection and autonomy. Due to reasons related to socio-economical conditions of the family (Bandeira, Seidl de Moura \& Vieira, 2009), but also due to particular 
cognitive and parental characteristics that are in agreement with the culture in which parents and children live (Henrich, Heine \& Norenzayan, 2010), it is admitted that parenthood may not have positive effects for the child development in the sense of promoting security and independence to children. Therefore, parents need to have the support of other family members (maternal grandmothers, usually) and/or institutions for children (shelters, foster home, and the like)

In Brazil, nowadays, there are also thousands of children in shelter institutions (Cavalcante, Costa \& Magalhães, 2012), which may indicate that parenthood has not been executedby many parents in desirable social conditions. In such circumstances, a rising issue for the human development is: in which conditions parenthood is being performed by parents in societies as the Brazilian one, in which about $45 \%$ of children and adolescents live in underprivileged families (IBGE, 2012).Moreover, which are the goals and socialization strategies prepared by them to educate their children with autonomy when parents themselves, commonly, lived in socio-economical conditions that were unfavorable for their full development? Contradictorily, it means to state that few studies have been dedicated to understand socialization goals for children who live in countries where $91 \%$ of the world population of children were born and live (Henrich, Heine \& Norenzayan, 2010).

The previously mentioned data necessarily leads to questioning about how parenthood is been performed in societies that, as the Brazilian one, have great number of children living in shelter institutions, an almost certain fateof those whose poverty conditions meet other social risk conditions (mistreatment, urban violence, abuse of alcohol and other substances in the family, physical and/or mental disorder). In those conditions a question needs to be asked: Which socialization goals have been offered by parents (and other caretakers that replace them in the daily care of children, such as grandparents) who live in contexts where poverty still holds children from been raised in the core of its family and cultural community?

In the specific case of grandparents that help or replace the parents in assuring their grandchildren development and several roles attributable to parent, it might be said that little is known on what they think about the child socialization in the early ages and the goals designed by them to guide this process. In a study performed in a shelter institution in the North region of Brazil Cavalcante, Costa e Magalhães (2012) concluded that mothers have been the usual caretaker of children before, during, and after the institutional sheltering; however, it tends to be closely followed by grandmothers on the daily basis of the child. Serrano (2008), in a similar study performed in the South of Brazil, demonstrated that mothers and grandmothers are reference figures in the family of children that live in institutions for social protection.

From what was exposed, it is noted that researches increasingly show that grandparents have shared or replaced parents in the socialization process of the grandchildren, however, not implying systematic investigations on the socialization goals designed for children in these special conditions. In this sense, this study aimed at investigating mothers' and grandmothers' psychological aspects, when acknowledged as reference figures in the families of children in shelter institutions, in order to enlighten who are those caretakers and which are the socialization goals defined by them for their children and grandchildren. The proposal is to discuss how aspects from the eco-cultural context that mothers and grandmothers live help defining 
the child socialization goals and the strategies for its consecution, possibly inspiring public policies more adequate to the reality of this population in social vulnerability conditions.

\section{Method}

The study was conducted in the largest institution for the care of children zero to six years in poverty and social vulnerability in a city located in northern region of Brazil. Participants were 20 mothers and 20 grandmothers when they visited their children at the host institution. Semistructured interview was conducted with two questions in order to collect data on participants sociodemographic (age, education, occupation and marital status) informations, the age and sex of the child and the socialization goals and strategies designed to reach them. The interview brought the following questions: "What qualities do you want in your child or grandchild as an adult?" and "What do you think is necessary so that he can develop these qualities?".

Mothers and grandmothers answered the questions contained in the questionnaire individually and their responses were audio recorded with their agreement. Then, answers were transcribed and subjected to content analysis according to defined categories from previous studies. As in the study of Bandeira, Seidl-de-Moura and Vieira (2009), the first question involved categories previously used by Harwood et al. (1999): self-improvement (AA) - longs for the child to become self-reliant and independent, and fully develop their talents and skills as an individual; Self-Control (AC) - expect a child to develop the ability to control negative impulses, such as greed, aggression or self-centeredness; Emotionality (iN) - you want the child to develop the capacity for emotional intimacy with others, and to be loved; Social Expectations (ES) - can become a hardworking, honest and law-abiding meeting with so expectations arising from the life of society; and Good Behavior (BC) - brings the concern that the child behaves appropriately, relate well with others, and is likely to play the roles expected with satisfaction (good father, good mother, good wife, good husband, among others), particularly when referring to living with the family.

The answers to the first question were also organized according to another system categories: 1) Maverick (understands the notion of the self as fundamentally distinct and unique, values independence, autonomy, self-esteem, happiness, and exercises self-control to become a better person; crave self-improvement and self-overcoming); 2) sociocentric (recognizes the construction of the self as dependent on its relationship with other beings; involves the notion of social interdependence; emphasizes the importance of respect between people, the social network, the membership in a given group or community). Thus, we considered responses that reinforce an individualistic perspective those that fall into the categories of self-improvement and self-control as the sociocentric when they could be enrolled in categories such as emotions, social expectations and good behavior.

The next moment, the answers to the second question were classified to reveal different possible strategies for action: Self-centered (CS), when mothers or grandparents saw themselves as role models for their children and grandchildren or other positive references, calling themselves the task of disciplining, advising, teaching by demonstration or participation; 
Centric Context ( CC ), which relates to good social opportunities that can put a child in the way they live, access to quality education, among others; and the Child centered (CCr), which highlights the child's active participation in the development of certain qualities or a personal predisposition for having a sense of autonomy that leads to decide what to do and which way to walk.

Further, we calculated the total number of responses given to the first question for each participant, and the percentage for each category considered for analysis. Regarding the second question, the procedure adopted included the analysis of qualitative data, identifying possible strategies for action and the percentage of them in relation to the participants. In addition, the data were statistically treated sociodemographic data of mother and grandparents, in order to build an overall profile of the participants.

The project was submitted to the Ethics Committee for Human Research of the Center for Tropical Medicine, Federal University of Pará, and was approved under the protocol №. 146/11.

\section{Results and discussion}

Socio-demographic characteristics of participants

Most of the twenty informer mothers lived in Belém, aged between 15 and 45 (M=27), had from one to seven children whose ages ranged between nine months to 11 years, and $80 \%$ of them didn't finish Elementary School. From the reasons for sending their children to shelters, the most common were: family negligence, abandonment, domestic violence, and sexual abuse. On the other hand, the twenty grandmothers aged between 37 and 70 years old ( $M=50.95), 57 \%$ didn't complete Elementary School, and $24 \%$ were illiterate. In what concerns to their professional occupation mothers and grandmothers were involved in informal jobs activities.

For the question "What qualities would like your child to have as an adult?" 61 valid answers were given by mothers and 64 by grandmothers, which represents an average of 3.05 and 3.04 for each group. In Table 1 the percentages were presented for each category of socialization goals analyzed.

It may be observed that mothers and grandmothers value four of the five categories in the same order. The social expectation category had a higher percentage, followed by proper demeanor, self-maximization, and emotionality, self-control was mentioned only by the mothers.

The social expectation category was the most mentioned one by mothers and grandmothers of children in institutional shelter. As examples of responses related to this category were the concern that their children have a profession in the future, attend college, are hardworking, study hard, and have a good character, in other words, that they manage to make something out of their lives. How strongly they emphasize the importance of education for their children and grandchildren socialization may be linked to the fact that these mothers and grandmothers 


\begin{tabular}{lcc}
\hline \multirow{2}{*}{ Categories } & Mothers $(\mathrm{n}=6 \mathbf{6 1})$ & Grandmothers $(\mathrm{n}=64)$ \\
\cline { 2 - 3 } & $\%$ & $\%$ \\
\hline Social Expectancy & 77 & 73 \\
ProperDemeanor & 15 & 19 \\
Sefl-maximization & 4 & 5 \\
Self-control & 2 & 0 \\
Emotionality & 2 & 3 \\
Total & 100 & 100 \\
\hline
\end{tabular}

Table 1. Response percentage of mothers and grandmothers in the socialization goals category.

see in education the possibility for their children to enter the school environment and reach social mobility through college education, as well as the opportunity for them to live with people different from their context, which may mean to broaden their social support network. The mentions about work demonstrate their will to see their children and grandchildren grow up with financial independence, for the mothers and grandmothers work on their own and don't have regular income. Mentioning work regards the possibility of having an increase in their income, hence, having their purchasing power increased, being treated with more dignity by the value provided by it, increasing self-esteem, and having the respect of others. Therefore, the goal of becoming a worker in the future seems to be based more on the feeling of dignity than on the notion of citizenship.

Sarti (2010) considers that underprivileged people attribute moral value to work, making it dignifying, since it enables social mobility through work and personal dedication. Therefore, work is considered an instrument that enables family life and makes it dynamic. Consequently, the interviewed women long for their children and grandchildren to become hardworking in the future, so they can contribute for the success of a collective project that is to improve its own life, as well as enabling the family to have social mobility, because it is expected from them to payback for the time and resources dedicated to their upbringing and care.

Secondly, it appears the category proper demeanor that gathers the goals from mothers and grandmothers that are concerned their child learn to have good manners in the social life, to relate to other people in a collaborative manner, and to perform the expected roles. The emphasis on this category can be explained by the preoccupations mothers and grandmothers have if they will be able to follow rules and norms established by the society and in agreement to the collective environment. For them, once the child is familiar with social norms it will easier to distinguish what is adequate from what is not. This is considered an important socialization goal because it represents the best way of living in society, especially in family.

In the continuance, the category self-improvement mentioned by the participants, gathered answers that demonstrate their concern with the children's and grandchildren's wellbeing once they are adults. This category gathers some characteristics regarding a better future, as for example, to be happy, to have a profession, among others. This kind of concern may be justified 
by the strength of a cultural model that is especially present in the most prosper, educated, industrialized, rich and democratic western societies (Henrich et al., 2010), that disseminated individualism and competitiveness as values that must be essential for the construction of the self. These are societies that, according to these authors, give importance to autonomy and professional accomplishments, in view of new demands of a capitalist society that needs to increase the individual's productive potential. These mothers and grandmothers hope their children self-maximize and are able to accomplish everything they couldn't for several reasons, chiefly, low income, little education, and little access to education and health services for them and their family members. In other words, they design for their children's future socialization goals based on achieving high education levels and a different job than the current one: socially recognized and better paid.

The category emotionality also shows up in the mothers' and grandmothers' speech expressing their hope for their children and grandchildren to be respectful, but also to be respected. To be treated with respect and, likewise, give respect to others is a moral value yet to be harvested in the preparation of children for living socially, mainly among popular sections and/or those who live away from most important urban nuclei (Moinhos et al., 2007; Silva \& Magalhães, 2011; Westphal et al., 2011), essentially because it contributes to cultivate reciprocity in family relations, as pointed out by Sarti (2010). The self-control category was mentioned only by mothers when demonstrated apprehension their children wouldn't be able to control negative impulses, which may lead to aggressive behavior towards parents, for example.

Admitting that individualist dimension gathers the self-maximization and self-control categories, and the sociocentric dimension includes the social expectation, emotionality and proper demeanor categories, Table 2 shows the general distribution of the answers given by mothers and grandmothers in these dimensions.

\begin{tabular}{lcccc}
\hline Categories & \multicolumn{2}{c}{ Mothers $(\mathbf{n}=\mathbf{2 0})$} & \multicolumn{2}{c}{ Grandmothers $(\mathbf{n}=\mathbf{2 0})$} \\
\cline { 2 - 5 } & $\boldsymbol{F}$ & $\%$ & $\boldsymbol{f}$ & \% \\
\hline Individualist & 4 & 6 & 3 & 5 \\
Sociocentric & 57 & 94 & 61 & 95 \\
Total & 61 & 100 & 64 & 100 \\
\hline
\end{tabular}

Table 2. Response percentage of mothers and grandmothers according to the individualist and sociocentric categories.

It is observed that both mothers and grandmothers mentioned predominantly traces of a sociocentric cultural model, appreciating more the posture of interdependence and the esteem for collectivity, as it was identified among agriculturalist mothers from Cameroon, and from villagers from India, studied by Keller et al. (2005), and other studies made in Brazil, including the North region (Silva \& Magalhães,2011).

In the analysis of the second question "What do you think it is necessary for him/her to develop these qualities?", 42 strategies were mentioned by mothers and 38 by grandmothers, grouped 
accordingly to the following categories: centered in the self, centered in the child, or centered in the context.

\begin{tabular}{lcc}
\hline \multirow{2}{*}{ Categories } & Mães $(\mathbf{n = 4 2 )}$ & Avós $(\mathrm{n}=\mathbf{3 8})$ \\
\cline { 2 - 3 } Centered in the self & $\%$ & $\%$ \\
Centered in the context & 48 & 55 \\
Centered in thechild & 28 & 29 \\
\hline
\end{tabular}

Table 3. Response percentage of mothers and grandmothers in socialization strategies categories.

The data indicate the convergence between the strategies used by mothers and grandmothers, first regarding the ones linked to the centered in the self category, secondly to the ones giving emphasis to factors associated to the context, and finally, to everything that concerns exclusively to the child's characteristics. These data are in agreement to the study of Moinhos et al. (2007), Bandeira et al. (2009), Diniz e Salomão (2010),, in which the most reported strategy was the one regarding the attributions from their role as primary caretakers and main family reference for the child. Those mothers and grandmothers believe the primary caretaker's role that was given to them by society makes them responsible for providing affection and daily attention to the children. It is necessary to note that such way of thinking stood out in the moment they watched their children and grandchildren being taken away from their daily lives and were living in a shelter institution, temporarily, for their ability to protect them, and educate them, was being questioned from the social and judicial standpoint, according to the child social protection legislation.

To what concern the strategies centered in the child, it is noted that mothers and grandmothers delegate to their children and grandchildren the responsibility to develop certain qualities, as illustrated in some statements.

\footnotetext{
"It is necessary that they study..." (M2)

"Study hard, have a good husband, and a good job..." (M5)

"Study a lot to reach their goals..." (M10)

"Their dedication to the studies..." (M13)
}

These statements also show that the participants transfer to their children and grandchildren the responsibility to reach the socialization goals designed by them. If, on one hand, it implies the notion of an active child who is capable of searching its own self-maximization, on the other hand, it suggests that the mothers' and grandmothers' comprehension of how the acquisition of abilities in the child socialization process takes place, chiefly in the early years, 
might be limited. Such apparent contradiction may be happening in a less proportion due to the lack of knowledge on how indispensible the adult supervision is in the early years, and more due to socio-economic conditions and traditional habits of the culture they are inserted, and they need to be responsible for the child's care and education. After all, to offer a stable and responsive care pattern from mothers and grandmothers depend, initially, on how the society and culture they are inserted define these terms, and secondly, on material conditions that enables to rethink practices and/or potentiate protection measures.

In this sense, the strategies centered in the context emphasize the importance of available resources in the family and social environments as fundamental strategies to achieve the designed socialization goals, either attenuating what might be prejudicial for the child, or potentiating the help from support networks formed by people and institutions (as it is the case of those sent to shelters and preschool). It is considered here the child's closest environment, in other words, the closest to the person in development, regarding the most remote dimensions, involving the resources the society may provide to this task in different forms (including the cultural valorization of socialization goals from parents and other family members, as grandparents).

Some studies indicate that it must not be strengthened the idea of a single procedure and/or more efficient one to lead parents and other primary caretakers to reach the socialization goals designed by them, for it is important to know the strategies they can easily make use of, or the ones they need to request support. Likewise, it is necessary to take into consideration the ecocultural conditions that guide the conception of a dominant parenthood in the context these goals were planned, the personal characteristics of the child, and the parental ethnotheories, and, clearly, mainly in the cases involving extreme poverty and other social vulnerability situations, the available means in the social support network that might help mothers and grandmothers in the task of raising and educating today, but looking at the future.

\section{Final considerations}

The present study aimed at approaching in an exploratory fashion the socialization goals of mothers and grandmothers of children in shelter institutions that lived in the North region in Brazil. Such aspects that constitute the parental ethnotheories in this society and culture were approached from evidences regarding what these caretakers long for their children and grandchildren, and the strategies planned by them to achieve these purposes.

In this sense, the results obtained bring contributions to the scarce literature destined to the discussion of this particular subject. Nonetheless, it is necessary to note some limitations of this study, such as the size of the sample. The parental cognition about the socialization goals were studied through their responses to two open questions, which demanded the analysis of the content of the participants' responses. Although the procedure for analyzing the content has been used in several investigations and are bringing relevant and consistent results, new instruments might be developed and/or adapted to be used in future studies, with bigger groups of parents (mother and father) and grandparents (grandmothers and grandfathers), 
including other regions of Brazil. Hence, the cultural models of parenthood of Brazilian parents may be better understood, as well as important aspects of the child development context that are built nowadays, enabling the comparison to the results from other cultures. In addition, other similar studies may stimulate more contextualized investigations, therefore, open new paths for the research of cultural dimensions on the human development.

Another aspect to be mentioned is the disclosure of the thoughts of caretakers of children who were withdrawn from the family living, their belief systems and moral standards, expectations or socialization goals that mothers and grandmothers have about how their children and grandchildren are and/or how they are going to be in the future. These pieces of information are important to the authorities, managers, technicians and educators that work in the shelter institution field, for they help to understand about the quality of care and possible influences on the child development.

\section{Author details}

Lília Iêda Chaves Cavalcante ${ }^{1}$ and Celina Maria Colino Magalhães ${ }^{1,2}$

1 Program in Behavior Theory and Research, Federal University of Pará, Brazil

2 CNPq Research Productivity - Level 2, Brazil

\section{References}

[1] Bandeira, T. A. T., Seidl-de-Moura, M. L.,Vieira, M. L. (2009). Metas de socialização de pais e mães para seus filhos. Journal of Human Growth and Development, , 19 (3), $445-456$

[2] Barroso, R. G. \& Machado, C. (2011). Definições, dimensões e determinantes da parentalidade. Psychologica, 52, 211-230.

[3] Bronfenbrenner, U. (1979). The ecology of human development: experiments by nature and design. Cambridge: Harvard University Press.

[4] Cavalcante, L.I.C., Magalhães, C.M.C., Costa, L. N. (2012). Caretaking behavior among siblings in children's shelters. Psicologia: Reflexão e Crítica (UFRGS. Impresso), 25 (1), 165-173.

[5] Diniz, P.K.C. \& Salomão, N.M.R. (2010). Metas de socialização e estratégias de ação paternas e maternas. Paidéa, 20 (46), 145-154

[6] Fundo das Nações Unidas para a Infância - UNICEF. (2012). Situação mundial da infância. Crianças em um mundo urbano. (B\&C Revisão de Textos, SP, Trad.). Brasília: Autor. 
[7] Harkness, S. \& Super, C. M. (1996). Parent's cultural beliefs systems: their origins, expressions and consequences, The Guilford Press: New York

[8] Harwood, R. L., Schoelmeirch, A., Schulze, P. A., Gonzalez, Z. (1999).Cultural diffrences. In Maternal Beliefs e Behaviors: A study of Middle-Class Anglo Puerto Rican Mother-

[9] Infant Pars in four everyday situations. Child Development ,70 (4) 1005-1016.

[10] Henrich, J., Heine, S., \& Norenzayan, A. (2010). The weirdest people in the world? Behavioral and Brain Sciences, 33, 61-135

[11] Kagitcibasi, C. (2005). Autonomy and relatedness in cultural context: Implications for self and family. Journal of Cross-Cultural Psychology, 36, 403-422.

[12] Keller, H., Lamm, B., Abels, M., Yovsi, R., Borke, J., Jensen, H., Papaligoura, Z., Holub, C., Lo, W., Tomiyama, A. J., Su, Y., Wang, Y., Chaudhary, N. (2006). Cultural models, socialization goals, and parenting ethnotheories: a multicultural analysis. Journal of Cross-Cultural Psychology, 37(2) 155-172.

[13] Keller, H., Voelker, S., \& Yovsi, R. D. (2005). Conceptions of parenting in different cultural communities. The case of west african nso and northern german women. Social Development, 14, 158-180.

[14] IBGE. Instituto Brasileiro de Geografia e Estatística. Síntese de indicadores sociais: uma análise das condições de vida da população brasileira. Rio de Janeiro: IBGE, 2012. http: //ibge.org.br/ (acessed 3 july 2012)

[15] Leyerdecker, B. Lamb, M. E. Harwood, R. L., Sholmerich, A. (2002). Mother's socialization goals and evaluation of deseirable and undesirable everyday situations in two diverse cultural groups. International Journal of Behavioral Development, 26 248-258.

[16] Maccoby, E. (2000). Parenting and its effects on children: on reading and misreading behavior genetics. Annual Review of Psychology, 51, 1-27.

[17] Mimi McEvoy, M., Lee, C., O’Neill, A., Groisman, A., Roberts-Butelman, K., Dinghra, K., \& Porder, K. (2005). Are there universal parenting concepts among culturally diverse families in an inner-city pediatric clinic? Journal of Pediatric Health Care, 19 (3), 142-150

[18] Moinhos, M.V.C., Lordelo, E. R., \& Seidl-de-Moura, M. L., (2007). Metas de socialização de mães baianas de diferentes contextos socioeconômicos.Journal of Human Growth and Development, , 17 (1), 114-125

[19] Moura, M. L. S., Lordelo, E. R., Vieira, M. L. ; Piccinini, C. A. , Siqueira, J. O., Magalhães, C. M. C., Salomão, N. M., Rimoli, A. (2008). Brazilian mothers' socialization goals: Intracultural differences in seven Brazilian cities. International Journal of Behavioral Development, 32 465-472. 
[20] Moura, M. L., Soares, I., Gomes, A., \& Bornstein, M. (2003). Socioeconomic status in Brazilian psychological research: II. Socioeconomic status and parenting knowledge. Estudos de Psicologia, 8, 385-392.

[21] Piccinini, C. A. \& Alvarenga, P. (2012). Maternidade e paternidade. A parentalidade em diferentes contextos. São Paulo: Casa do Psicólogo.

[22] Roy, P. \& Rutter, M. (2006). Institutional care: associations between inattention and early reading performance. In: Journal of Child Psychology and Psychiatry, 41, 480-487.

[23] Roy, P., Rutter, M. \& Pickles, A. (2000). Institutional care: risk from family background or pattern of rearing? In:: Journal of Child Psychology and Psychiatry, 41, 139-149.

[24] Sarti, C. A. (2010). A Família como Espelho: Um Estudo sobre a Moral dos Pobres. Cortez: São Paulo

[25] Serrano, S. A. Quem são as crianças institucionalizadas e suas famílias? Refletindo sobre os indicadores de abrigamento em Ribeirão Preto. (2011). In: Maria Clotilde Rossetti-Ferreira; Solange Aparecida Serrano; Ivy Gonçalves de Almeida. O acolhimento institucional na perspectiva da criança. São Paulo: Hucitec. pp 86-118.

[26] Silva, R. A. \& Magalhães, C.M.C. (2011). Crenças sobre práticas: estudo sobre mães primíparas de contexto urbano e não-urbano. Journal of Human Growth and Development, 21, (1), 39-50.

[27] Virasiri, S., Yunibhand, J. \& Chaiyawat, W. (2011) Parenting: What Are The Critical Attributes? Journal of The Medical Association of Thailand, 94 (09), 1109-1116

[28] Vegas, E. \& Santibáñez, L. (2010). América Latina. La promesa del desarrollo en la primera infância en América Latina y El Caribe. Washington, DC, Bogotá, Colômbia: Banco Mundial en coedición con Mayol Ediciones S.A.

[29] Westphal, J. P., Vieira, V. \& Vieira, M. L. (2010). O que mães pensam sobre seus filhos em três regiões distintas do estado de Santa Catarina. Psicologia Argumento (PUCPR. Impresso), 28, 235-246.

[30] Zucker E. \& Howes C. (2009). Respectful relationships: Socialization goals and practices among mexican mothers. Infant Mental Health Journal, 30(1), 501-522. 